\title{
Static and dynamic response of ultra-fast annealed advanced high strength steels
}

\author{
Florian Vercruysse ${ }^{1, *}$, Felipe M. Castro Cerda $^{2}$, Roumen Petrov ${ }^{1}$ and Patricia Verleysen ${ }^{1}$ \\ ${ }^{1}$ EEMMECS, University Gent, Tech Lane Science Park Campus A Gent, Belgium \\ ${ }^{2}$ Department of Metallurgical Engineering, Universidad de Santiago de Chile, Av. Lib. Bdo. O’Higgins 3363, Estación Central, Santiago \\ de Chile, Chile.
}

\begin{abstract}
Ultra-fast annealing (UFA) is a viable alternative for processing of $3^{\text {rd }}$ generation advanced high strength steels (AHSS). Use of heating rates up to $1000^{\circ} \mathrm{C} / \mathrm{s}$ shows a significant grain refinement effect in low carbon steel $(0.1 \mathrm{wt} . \%)$, and creates multiphase structures containing ferrite, martensite, bainite and retained austenite. This mixture of structural constituents is attributed to carbon gradients in the steel due to limited diffusional time during UFA treatment. Quasi-static (strain rate of $0.0033 \mathrm{~s}^{-1}$ ) and dynamic (stain rate $600 \mathrm{~s}^{-1}$ ) tensile tests showed that tensile strength of both conventional and UFA sample increases at high strain rates, whereas the elongation at fracture decreases. The ultrafast heated samples are less sensitive to deterioration of elongation at high strain rates then the conventionally heat treated ones. Based on metallographic studies was concluded that the presence of up to $5 \%$ of retained austenite together with a lower carbon martensite/bainite fraction are the main reason for the improved tensile properties. An extended stability of retained austenite towards higher strain values was observed in the high strain rate tests which is attributed to adiabatic heating. The extension of the transformation induced plasticity (TRIP) effect towards higher strain values allowed the UFA-samples to better preserve their deformation capacity resulting in expected better crashworthiness.
\end{abstract}

\section{Introduction}

Driven by stringent regulations for passenger safety, $\mathrm{CO}_{2}$ emissions and fuel consumption, the most recently developed advanced high strength steels (AHSSs) for the automotive industry offer a good combination of strength and ductility [1-2] . Moreover, these properties are maintained at the high strain rates typically met in a car crash. Using AHSSs the weight of a car can be significantly reduced without compromising the passenger safety [1].

At present, a third generation of AHSSs, which does not require, or at least contains, less expensive alloying elements which is still the main drawback of the $2^{\text {nd }}$ generation, is considered as realistic approach. To this generation among the others, belong steel processed via quenching and partitioning (Q\&P), medium Mn steel and steels processed via ultra-fast annealing (UFA) (Also known as rapid heating or "flash" annealing). Although some recent publications show that the UFA steels could be made industrially feasible, still UFA of steel is considered as an "exotic " treatment, mainly applicable on small size samples in laboratory conditions [3-5]. However all result for use of ultrafast heating rates in the range between $400{ }^{\circ} \mathrm{C} / \mathrm{s}$ and $1500{ }^{\circ} \mathrm{C} / \mathrm{s}$ followed by quenching (or quenching and partitioning) on the existing AHSS showed increase in both the yield strength and tensile strength together with increase in elongation at fracture [6]. In general, the refined microstructure coupled with findings of dispersed martensite/bainite/austenite obtained after UFA gives rise to an increase in both strength and ductility [5]. However, until now all results for strength and elongation of UFA steels are obtained via static or quasistatic tensile test on small, standard size samples [5] but there is no data about the behaviour of the UFA steel in the dynamic loading conditions which are more realistic in case of car accident.

Since UFA steels are of interest for the automotive industry in impact absorbing parts [7], present study focusses on how thermal processing parameters affect the mechanical properties of the steels tested in static and dynamic loading conditions. Special emphasis is put on properties which are important for crash applications, i.e. strength levels, elongation that reflects in the energy absorption capacity of steel.

\section{Materials}

The steel used in this work has the chemical composition, shown in Table 1. This composition is typical for the DP780 (industrial grade) steel.

The annealing experiments are carried out by means of a Gleeble 3800 thermomechanical simulator on 40x60x1.5 $\mathrm{mm}^{3}$ cold rolled strips. Three K-type thermocouples, spot-welded at different locations,

Corresponding author: florian.vercruysse@,ugent.be 
allowed to control the heating and cooling cycles, to monitor the thermal gradients in the samples and hence to determine the homogeneous heat treated zone of the strips. For all samples, the cooling rate after UFA is $\approx$ $120^{\circ} \mathrm{C} / \mathrm{s}$ which is higher than the critical quench rate of $-80{ }^{\circ} \mathrm{C} / \mathrm{s}$ for this steel.

Table 1. Chemical composition of steel used (wt \%).

\begin{tabular}{lllllll}
\hline Steel & $\mathbf{C}$ & Mn & Nb & Cr & Mo & Fe \\
\hline DP780 & 0.11 & 1.876 & 0.027 & 0.753 & 0.179 & Bal. \\
\hline
\end{tabular}

The samples are heated with three different heating rates (HR) of 10,400 and $1000{ }^{\circ} \mathrm{C} / \mathrm{s}$ up to three different peak temperature $\left(\mathrm{T}_{\mathrm{p}}\right)$, namely 770,790 and $825^{\circ} \mathrm{C}$ and immediately quenched (isothermal holding time was less than $0.3 \mathrm{~s}$ ) afterwards. Soaking time was kept sufficiently low as it was reported that a pronounced isothermal holding rapidly reverses the positive effects of high heating rates[8]. The peak temperatures are selected in the intercritical annealing range in order to obtain after quenching a dual phase microstructure with a 50:50 ferrite/martensite. According the thermodynamic calculations with Thermocalc a "parent" structure with $50 \%$ austenite and $50 \%$ ferrite in this steel exists at 770 ${ }^{\circ} \mathrm{C}$. However, since increasing heating rates are reported to shift the transformation region to higher temperatures [9], additionally, two higher peak temperature $-790{ }^{\circ} \mathrm{C}$ and $825^{\circ} \mathrm{C}$ - are considered.

\section{Experimental techniques}

The microstructures of the steel samples are investigated by scanning electron microscopy (SEM). Contrast is created by etching with a $4 \% \mathrm{Nital}\left(4 \% \mathrm{HNO}_{3}\right.$ dissolved in ethanol). Coupled with the SEM, electron backscattered diffraction (EBSD) system was used for data acquisition. EBSD scans are performed with a sample tilt of $70^{\circ}$, working distance of $16 \mathrm{~mm}$, accelerator voltage of $20 \mathrm{kV}$, and step size of $130 \mathrm{~nm}$ in a hexagonal scan grid. The grain size and the fractions of martensite, recrystallized ferrite and unrecrystallized ferrite are determined from the EBSD data.

The fraction of retained austenite prior to and after mechanical testing is determined by XRD measurement using a Siemens Kristalloflex D5000 diffractometer operating with a Mo- $\mathrm{K}_{\alpha}$ source at $40 \mathrm{kV}$ and $40 \mathrm{~mA}$. All scans are performed with a step size of $0.03^{\circ}$ and $20 \mathrm{~s}$ dwell time. The retained austenite fraction is determined based on the $\{200\} \alpha,\{211\} \alpha,\{220\} \gamma$ and $\{311\} \gamma$ diffraction peaks after subtracting the $\mathrm{K} \alpha_{2}$ and the background radiation from the raw data.

To characterize the quasi-static mechanical properties, a conventional Instron ${ }^{\mathrm{TM}} 5569$ tensile test device equipped with a $50 \mathrm{kN}$ load cell is used. The tensile tests are performed in the rolling direction at room temperature and with a nominal strain rate of $0.0033 \mathrm{~s}^{-1}$.

Since the UFA treatment is only applied to a limited area, sub-sized tensile samples have to be used. The dogbone sample geometry with gauge length of $5 \mathrm{~mm}$ was selected based on hardness profile of the UFA treated sample.

A speckle pattern is applied for 3D-Digital Image Correlation (DIC) purpose. The speckles have an average diameter of $\approx 135 \mu \mathrm{m}$. The zero-mean normalized cross correlation (ZNCC) algorithm is used for the DIC analysis with a subset size of 41 pxls, step size of 14 pxls and a strain window of 15 pxls.

To characterize the dynamic properties of samples, split Hopkinson tensile bar (SHTB) experiments are well established [10]. Because of its limited size, the sample geometry can straightforwardly be used for the dynamic tests (strain rates of $600 \mathrm{~s}^{-1}$ ) as well. Indeed, for SHTB tests the use of small samples is mandatory [11]. Aiming at the same boundary conditions as for the static tests, pins are used to hold the sample between the bars. Indeed, major advantage of the use of identical sample geometries and boundary conditions in the static and dynamic tests, is that the differences between the test results can be fully attributed to the effect of strain rate on the material behaviour [11].

\section{Results}

The initial microstructure is primarily composed of cold deformed ferrite and pearlite but is transformed after heat treatment into a microstructure consisting of a mixture of ferrite and martensite (Fig. 2). Independently of the heating rates, in the samples heated to peak temperatures of $\sim 770{ }^{\circ} \mathrm{C}$, all ferritic grains are nonrecrystallized (Fig. 2 a,d,g). However, samples heated at $10{ }^{\circ} \mathrm{C} / \mathrm{s}$ to temperatures above $790^{\circ} \mathrm{C}$ (Fig. 2 b,c) are almost fully recrystallized whereas the UFA treated samples are still to a large extent in the unrecrystallized state. In addition, at all three heating rates, martensite forms along bands in the samples heated to $\sim 770^{\circ} \mathrm{C}$ (Fig. 2 a, d and g). SEM image, show that the martensite, denoted with the dotted ellipsis, is actually a mixture of martensite and bainite with islands of retained austenite. Such mixture of phases could be an indirect indication of the existence of carbon gradients in the austenite before quenching.

The phase fraction of martensite and the corresponding average grain diameter of martensite are shown in Fig. 1. In samples heated at $400{ }^{\circ} \mathrm{C} / \mathrm{s}$ and $1000{ }^{\circ} \mathrm{C} / \mathrm{s}$, the martensite fraction reaches a maximum of $\sim 45 \%$ at $\sim 803$ ${ }^{\circ} \mathrm{C}$ and $\sim 783{ }^{\circ} \mathrm{C}$, respectively, and decreases slightly for the highest peak temperatures. The martensite fraction of samples heated at $10{ }^{\circ} \mathrm{C} / \mathrm{s}$ exhibits the opposite tendency, decreasing to a minimum of $\sim 42 \%$ at $791{ }^{\circ} \mathrm{C}$ and increases with increasing peak temperature.

The static mechanical data, obtained using the technique described in section 3, are presented in Fig. 3. They show the influence of both peak temperature and heating rate on the yield strength (YS), ultimate tensile strength (UTS) and fracture strain derived from local DIC measurements and energy absorbed by the material per volume unit determined as the area under the engineering stress/strain curve.

The samples heated to $770{ }^{\circ} \mathrm{C}$ at $10{ }^{\circ} \mathrm{C} / \mathrm{s}$ show a higher ultimate tensile strength $(+300 \mathrm{MPa})$, though reduced deformation capacity $(-0.1-0.2)$, compared to the 
samples subjected to higher heating rates $\left(400{ }^{\circ} \mathrm{C} / \mathrm{s}\right.$ and $1000{ }^{\circ} \mathrm{C} / \mathrm{s}$ ). At peak annealing temperature of $770{ }^{\circ} \mathrm{C}$, no significant differences are observed in the tensile response of samples heated at $400{ }^{\circ} \mathrm{C} / \mathrm{s}$ and $1000{ }^{\circ} \mathrm{C} / \mathrm{s}$ : the failure strain derived from local DIC measurements of the sample heated at the highest heating rate is slightly higher $(+0.07)$ compared to $400{ }^{\circ} \mathrm{C} / \mathrm{s}$ treated samples, the UTS slightly lower (-40 MPa).
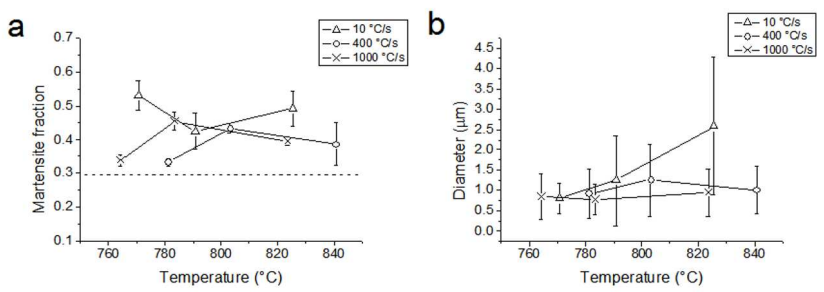

Fig. 1. Fraction (a) and average diameter (b) of martensite as a function of the peak annealing temperature for different heating rates.

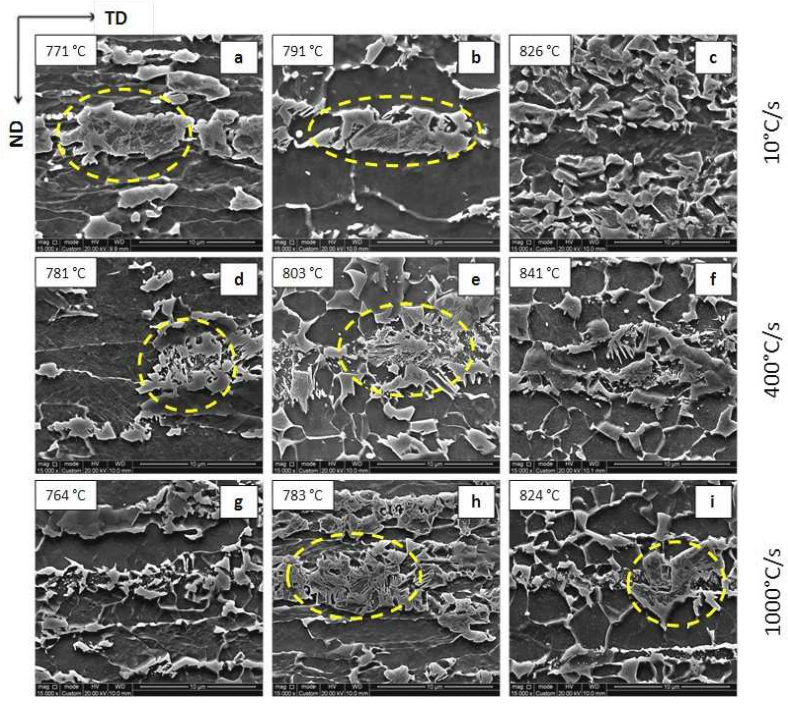

Fig. 2. SEM micrographs of samples heated at $10^{\circ} \mathrm{C} / \mathrm{s}(\mathrm{a}-\mathrm{c})$, $400{ }^{\circ} \mathrm{C} / \mathrm{s}$ (d-f), and $1000{ }^{\circ} \mathrm{C} / \mathrm{s}$ (g-i) to different peak temperatures, as indicated in each micrograph. Regions containing a complex mixture of martensite and bainite with islands of retained austenite are indicated with yellow ellipses.

From all samples heated to a peak temperature of $790^{\circ} \mathrm{C}$, the samples heated at a conventional rate of 10 ${ }^{\circ} \mathrm{C} / \mathrm{s}$ have the lowest strength. Remarkably, the strength of the $400{ }^{\circ} \mathrm{C} / \mathrm{s}$ treated samples seems to be hardly affected by the increase of the peak annealing temperature from $770{ }^{\circ} \mathrm{C}$ to $790{ }^{\circ} \mathrm{C}$. However, a significant increase of the strain at fracture is clear in 10 ${ }^{\circ} \mathrm{C} / \mathrm{s}$ and $400{ }^{\circ} \mathrm{C} / \mathrm{s}$ treated samples. The samples heated at $1000{ }^{\circ} \mathrm{C} / \mathrm{s}$ show the most pronounced decrease in deformation capacity, together with increase in strength. At peak annealing temperature of $825^{\circ} \mathrm{C}$, the samples treated at the conventional heating rate are characterized by an increase in UTS and decrease in ductility when comparing with results obtained at $790{ }^{\circ} \mathrm{C}$. For the samples heated at $400{ }^{\circ} \mathrm{C} / \mathrm{s}$, small differences are observed between the tensile properties of samples heated up to $790{ }^{\circ} \mathrm{C}$ and $825^{\circ} \mathrm{C}$. For the highest heating rate on the contrary, distinct differences in the properties can be noticed between samples quenched from peak temperatures of $790{ }^{\circ} \mathrm{C}$ and $825{ }^{\circ} \mathrm{C}$ : at the highest peak temperature, the tensile strength decreases with \pm 300 $\mathrm{MPa}$, the deformation capacity increased by $\pm 50 \%$.


Fig. 3. Annealing temperature dependency of yield strength (a), UTS (b) strain at failure (c) and energy absorption capacity (d) under varying heating rates.

The effect of the peak annealing temperature on the yield strength is well pronounced. For the samples heated at $10{ }^{\circ} \mathrm{C} / \mathrm{s}$, the yield strength decreases twice when the peak temperature is increases from $770{ }^{\circ} \mathrm{C}$ to $790{ }^{\circ} \mathrm{C}$, and again increase to $800 \mathrm{MPa}$ after quenching from $825^{\circ} \mathrm{C}$. A similar trend is observed for the samples treated at the $400{ }^{\circ} \mathrm{C} / \mathrm{s}$, however, the increase for the highest peak temperature is much smaller. Samples treated at 1000 ${ }^{\circ} \mathrm{C} / \mathrm{s}$, on the contrary, show a strong increase of the YS when the peak temperature is increased from 770 to 790 ${ }^{\circ} \mathrm{C}$, however, the lowest value is reached at the highest peak temperature.

The strain at failure as a function of peak temperature and for the different heating rates is presented in Fig. 3 c. As is often the case with metallic alloys, the deformation capacity follows a trend opposite to the UTS: it increases when the UTS decreases and vice-versa.

The energy absorbed by the sample is shown in Fig. $3 \mathrm{~d}$. The absorbed energy increases with the increase of the peak temperature in samples heated at 10 and $400{ }^{\circ} \mathrm{C} / \mathrm{s}$. However, samples heated to $790{ }^{\circ} \mathrm{C}$ at $1000{ }^{\circ} \mathrm{C} / \mathrm{s}$ show a low energy absorption than the other samples. Overall it can be stated that samples quenched from high temperatures and at high heating rates all have (slight to significant) higher energy absorption potential than their conventional heated counterparts.

Table 2. Retained austenite fraction (\%) a.f.o. temperature and heating rate. Retained austenite fraction after Hopkinson test $(\mathrm{AH})$ was also included.

\begin{tabular}{lccc}
\hline & $\mathbf{7 7 0}^{\circ} \mathbf{C}$ & $\mathbf{7 9 0}^{\circ} \mathbf{C}$ & $\mathbf{8 2 5}^{\circ} \mathbf{C}$ \\
\hline $\mathbf{1 0}{ }^{\circ} \mathbf{C} / \mathbf{s}$ & $\mathrm{x}$ & $\mathrm{x}$ & $\mathrm{x}$ \\
\hline $\mathbf{4 0 0}^{\circ} \mathbf{C} / \mathbf{s}$ & 3.56 & 4.80 & 1.96 \\
\hline $\mathbf{1 0 0 0}{ }^{\circ} \mathbf{C} / \mathbf{s}$ & 4.24 & 2.97 & 0.86 \\
\hline $\mathbf{A H}$ & & 1.9 & \\
\hline
\end{tabular}


The retained austenite fractions derived from XRD measurement are depicted in Table 2. The samples heat treated at a conventional rate of $10{ }^{\circ} \mathrm{C} / \mathrm{s}$ showed no measurable amount of retained austenite and is therefore not shown in the table. Samples treated at $400{ }^{\circ} \mathrm{C} / \mathrm{s}$ and $1000{ }^{\circ} \mathrm{C} / \mathrm{s}$ showed presence of up to $5 \%$ of retained austenite. However, higher peak annealing temperatures cause the retained austenite fraction to drop significantly $(75 \%)$. An exception here is the $400{ }^{\circ} \mathrm{C} / \mathrm{s}$ treated sample where the maximum retained austenite fraction is observed at $790{ }^{\circ} \mathrm{C}$ peak annealing temperature rather than $770{ }^{\circ} \mathrm{C}$ in the $1000{ }^{\circ} \mathrm{C} / \mathrm{s}$ heated samples.

Material properties are dependent not only on the microstructure but they are highly influence by the testing conditions (temperature, deformation mode, specimen dimensions, strain rate, etc.) [12]. AHSS, developed for automobile industry, therefore are tested at high strain rate tensile experiments to evaluate their crash resistance potential. The samples proposed here are subjected to strain rates of $\approx 600 \mathrm{~s}^{-1}$.

The samples for high strain rate tensile test were selected among the best performing samples at quasistatic tensile tests, namely the samples heated at 10 and $400{ }^{\circ} \mathrm{C} / \mathrm{s}$ to the intercritical temperature range of $790^{\circ} \mathrm{C}$. The presence of highest fraction of retained austenite further strengthens this believe as the TRIP effect is known to be beneficial for strength and ductility even more at high strain rate tests caused by extended retained austenite stability [13].
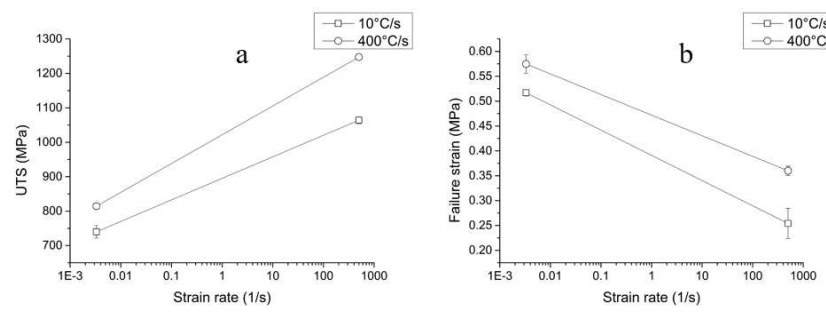

Fig. 4. Influence of strain rate on UTS and strain at failure for samples treated till $790{ }^{\circ} \mathrm{C}$ at heating rates of resp. $10{ }^{\circ} \mathrm{C} / \mathrm{s}$ and $400{ }^{\circ} \mathrm{C} / \mathrm{s}$.

Compared to the results obtained at low strain rates (described in previous section) increase in YS, UTS and decrease in strain at fracture are observed (Fig. 4). An influence of heating rate can be concluded, as higher heating rates seem to be altered to lesser extent by increased strain rate.

The results from samples heated up to $790{ }^{\circ} \mathrm{C}$ at $10{ }^{\circ} \mathrm{C} / \mathrm{s}$ as well as at $400{ }^{\circ} \mathrm{C} / \mathrm{s}$ are presented below. These two conditions are selected as they consist out of very similar amount of martensite and present the potential of UFA in the production of dual phase (complex phase) steels.

\section{Discussion}

The UFA treatments of the steel considered in this study generate a complex microstructure consisting of ferrite, bainite, and martensite. The presence of martensite/bainite/retained austenite and their distribution in the ferrite matrix indicate that carbon gradients exist in the grains, as also reported in literature
[14]. The ferrite is surrounded by bainite and martensite (Fig. 2). Such microstructure is reported for UFA produced steels and it differs from the classical ferritemartensite structure of the dual-phase steel.

A shift in recrystallization of ferrite to higher temperatures is observed (Fig. 2) with increasing heating rate. This observation is in agreement with data in[4] and will have important implications on mechanical behavior due to grain refinement of ferrite and martensite [5].

The phase transformation starting in an unrecrystallized (or partially recovered) ferrite grain promotes the formation of numerous nuclei resulting in smaller grains which is observed here and been reported [5]. The grain size presented here is of martensite. It has been chosen to show it in this manner as the grain refinement will be more pronounced in this phase due to the double transformation which is absent in the ferrite that only recrystallizes (neglecting ferrite that originates from the massive back transformation). The trends are the same for ferrite as is for martensite therefore it was opted to only plot the latter in this work as this will have had the dominant effect on the property changes [15].

The lower martensite fraction obtained for UFA samples than in conventionally heated samples is caused by the $\mathrm{Ac}_{1}$ and $\mathrm{Ac}_{3}$ temperatures shifting upward with increase heating rate. Additionally a decreased martensite fraction observed (within the same heating rate) when the peak annealing temperature is increased to $825^{\circ} \mathrm{C}$ is attributed to the change in transformation mechanism. Part of the ferritic grains, will upon heating, transform to austenite (and back upon cooling) in an interface controlled manner, resulting in a lower martensite fraction than for low conventional heating rates of $10{ }^{\circ} \mathrm{C} / \mathrm{s}$ [16]. This will only occur when the driving force for nucleation is sufficiently high, which is created when phase transformation can occur out of unrecrystallized ferrite and the sample is heated to a sufficiently high temperature. With increasing heating rate this 'threshold' temperature is lowered and can therefore be reached.

A fraction of $3-5 \%$ retained austenite (Table 2) is measured in the UFA samples. The inherent short nature of the UFA treatment causes carbon to be heterogeneously distributed in the steel. In the zones, where cementite is partially dissolved, the austenite could be sufficiently carbon enriched and hence is stabilized in subsequent quenching step. The reduction in retained austenite fraction measured at high peak annealing temperatures arises from increased carbon diffusivity and thus levelling out of the high carbon zones.

Samples treated at a conventional heating rate showed a decreasing YS and UTS when peak annealing temperature was increased from $770{ }^{\circ} \mathrm{C}$ to $790{ }^{\circ} \mathrm{C}$. This severe drop $(\approx 450 \mathrm{MPa}$ for YS and slightly less for UTS) is explained by 2 factors: recrystallization (Fig. 2) and martensite fraction (Fig. 1). At $790{ }^{\circ} \mathrm{C}$ the sample is (almost) completely recrystallized, therefore a decrease in the YS occurs as yield will start at lower strains in unstrained 'new' ferritic grains. Second, a decrease in martensite fraction further explains this behavior. At 825 ${ }^{\circ} \mathrm{C}$, however, no further recrystallization is to be taken 
into account as at $790{ }^{\circ} \mathrm{C}$ the sample was fully recrystallized. The increase in YS and UTS here is explained by the again increased martensite fraction. The grain growth that is observed when the peak annealing temperature is increased will to some extent reduce the UTS of the sample; although the changes in martensite fraction coupled with the recrystallization occurring will be the dominating influences.

Samples treated at $1000^{\circ} \mathrm{C} / \mathrm{s}$ showed different trends. At $770{ }^{\circ} \mathrm{C}$ it can be seen (similarly for samples treated at $400{ }^{\circ} \mathrm{C} / \mathrm{s}$ ) that the samples are characterized by a lower YS and UTS compared to conventionally heated samples. The lower martensite fraction, caused by shift of $\mathrm{Ac}_{1}$ and $\mathrm{Ac}_{3}$, is the main reason for this. Increasing the peak annealing temperature to $790{ }^{\circ} \mathrm{C}$ causes a steep increase, rather than decrease in YS and UTS. The increase in martensite fraction, compared to $770{ }^{\circ} \mathrm{C}$, together with the absence of recrystallization to temper this increase explains this behaviour. Overall this results in an increase in YS and UTS. There properties however drop again when peak annealing temperature is increased to $825{ }^{\circ} \mathrm{C}$. The occurrence of recrystallization, although not completely finished together with the reduction of martensite fraction cause this decrease. When surpassing the $T_{\text {massive }}$ temperature, as presented before, fraction of ferrite transforms to austenite and back in an interface controlled way, the martensite fraction is reduced with respect to expectations [16]. The reduced martensite fraction is dominating this mechanical behaviour. Grains remain small even at increasing peak annealing temperature which positively influences the YS, UTS and later discussed deformation properties.

Samples treated at $400{ }^{\circ} \mathrm{C} / \mathrm{s}$ show quite remarkably stable YS and UTS values throughout the peak annealing temperatures reaching from $780{ }^{\circ} \mathrm{C}$ to $840^{\circ} \mathrm{C}$. From 780 ${ }^{\circ} \mathrm{C}$ to $804{ }^{\circ} \mathrm{C}$ a small decrease $(\approx 100 \mathrm{MPa})$ can be observed and further increase to $825^{\circ} \mathrm{C}$ has hardly any influence. Similarly to $1000{ }^{\circ} \mathrm{C} / \mathrm{s}$ heated samples a drop in martensite fraction can be observed when peak annealing temperature is increased from $804{ }^{\circ} \mathrm{C}$ to 840 ${ }^{\circ} \mathrm{C}$. A decrease in YS and UTS however is absent. It can be stated that the recrystallization here together with the reduced martensite fraction can be a reason for reduction in YS and UTS values. This is levelled out by the fact that lower amount of retained austenite was observed (Table 2). The reduced retained austenite fraction indicates a more homogeneous carbon distribution resulting in martensite with an overall higher carbon content rather than few localized high carbon martensite islands as a result of retained austenite transformation. As carbon content is a main strengthening component in martensite this homogeneous carbon distribution has caused an overall strengthening of the martensite negating the weakening effects expected with recrystallization and overall reduced martensite fractions [17].

The strain at failure in conventionally heated samples $\left(10^{\circ} \mathrm{C} / \mathrm{s}\right)$ is in accordance to UTS (and YS) results where increases and decreases can be linked with variations in martensite content. Higher heating rates samples however show some deviations compared with the conventionally heated ones. Firstly their martensite fractions is lower than in those created via $10^{\circ} \mathrm{C} / \mathrm{s}$ heating due to the general influence of the heating rate on $A_{C 1}$ and $A_{C 3}$ [8-9] and further by transformation mechanism of austenite that changes to massive rather than diffusion controlled. The lower martensite fraction helps to explain the overall higher deformation capability of the material. Secondly, the presence of retained austenite, originating from carbon rich zones due to reduced diffusion times, further enhances the differences in deformation capabilities between high and conventional heating rates. This behavior is best observed at the sample treated to $804^{\circ} \mathrm{C}$ at $400^{\circ} \mathrm{C} / \mathrm{s}$. Thirdly grain refinement that is observed, and which is in accordance with literature, even more accentuate this behavior [5-6]. The shift in the onset of recrystallization, confirmed at higher heating rates $[4,18]$, is expected to negatively influence the deformation capabilities of the steels annealed at intermediate temperatures $\left(790^{\circ} \mathrm{C}\right)$. However this negative effect is masked in the case of $400^{\circ} \mathrm{C} / \mathrm{s}$ by the presence of retained austenite, which contributes to the plasticity via the TRIP effect. Samples treated at $1000^{\circ} \mathrm{C} / \mathrm{s}$ do show significant reduced strain at failure but the increased martensite fraction most likely is the dominating factor.

In accordance to the derived energy absorption capabilities of the material it can be concluded that with increasing heating rate the total energy absorption increases. The grain refinement and presence of retained austenite coupled with low-carbon martensite may explain this energy absorption increase of $5-30 \%$. The observation that 'all' austenite is transformed during straining, as there is no measureable fraction afterwards, proves the transformation of austenite. This allows the material to plastically deform to larger extent and still reach sufficient strength resulting in the improved energy absorption. The overall low martensite fraction resulting in high deformation capability however will influence these results to certain extent. Further it has to be noted that this energy absorption has been derived from uniaxial low strain rate tensile test which is not directly transferable to deformation states that occur during car crashed as high strain rate as well as complex, deformation state might yield deviating results.

AHSS steels where developed to be used in automotive applications and therefore mechanical test at high strain rates are necessary to validate its potential. It is opted to evaluate the samples produced till $790{ }^{\circ} \mathrm{C}$ peak annealing temperature and conventional heating rates are compared with $400{ }^{\circ} \mathrm{C} / \mathrm{s}$ one. Increase in UTS is easily observable (Fig. 4), and has been reported numerous times to be the normal response when strain rate is increased in 5 orders of magnitude [19]. Shortened times for dislocations to response on the more sudden stress increase is a main cause behind the observed increase in YS and UTS. Similarly, a decrease in the strain at failure could be expected and is surely observed. Significantly improved deformation properties of UFA treated steels can be seen when the conventional and the $400{ }^{\circ} \mathrm{C} / \mathrm{s}$ samples are compared. The ultra-fast heated sample is characterized to better preserve the deformation capabilities of the steel. This results in a lesser decrease of potential for energy absorption during 
high strain rate deformation. More refined grains (25\%), as can be seen in Fig. 1, are reported to have a beneficial effect of the mechanical properties in high strain rate environment [20]. Further, the complex nature of low carbon martensite/bainite together with the retained austenite, created due to the limited diffusion times, will improved the deformation capabilities. Lower carbon martensite is inherently more ductile than the higher carbon one that is observed in conventional heated samples [17]. However, a large influence of this retained austenite in the ultra-fast heated sample tested here is expected. The retained austenite is expected upon deformation to transform toward high strength martensite. This transformation will influence the possible total deformation of sample. Adiabatic heating of the sample, which is an effect of high strain rate testing, can influence the transformation stability of retained austenite. This is observed in Hopkinson tests performed on TRIP steels [13]. Prolonging the transformation point, towards high strain values can therefore have had an effect on the better preservation of deformation capability when strain rates are increased. The prolonging of the transformation point to higher strains is proven by the presence of retained austenite in the high strain rate samples tested after fracture and the absence of it in the static tensile test.

\section{Summary and conclusions}

Tensile properties of DP780 steel treated with heating rates of 10,400 and $1000{ }^{\circ} \mathrm{C} / \mathrm{s}$ to the intercritical temperature range and subsequently quenched without isothermal soaking were studied in static and dynamic conditions.

An overall increased energy absorption when high heating rates are applied, indicates the benefit of an UFA treatment. This mechanical behaviour is improved due to interaction of phase transformation and recrystallization, complex/non-equilibrium phases, the presence of retained austenite (up to 5\%) and grain refinement.

The smaller deterioration of failure strain when compared to the conventional heating rate is the key result of the extended austenite stability caused by adiabatic heating at high strain rate tests. This phenomenon is observed in the ultra-fast heated samples.

Shift of the recrystallization start to higher temperatures was observed when high heating rates were applied. As a consequence, a low recrystallized fraction is present in the samples heated at high heating rates to low peak annealing temperatures, which results in an increase YS of these samples.

The lower martensite fraction observed in the UFA samples heated to higher peak annealing temperatures is due to the massive ferrite - austenite -ferrite transformation.

Limited time for carbides dissolution and carbon diffusion causes heterogeneous carbon distribution in parent austenite which leads to the formation of microstructure which is a mixture of retained austenite, martensite, bainite and ferrite.
Florian Vercruysse acknowledges gratefully the financial support by the OptiQPap RFCS project.

\section{References}

1. J. G. Lopez, L. Samek, P. Verleysen, Rev. de Met. (2012)

2. R. Kuziak, R. Kawalla, S. Waengler, Arch. Civ. Mech. Eng., 8 (2008)

3. A. C. D. Reis, L. Bracke, R. Petrov, W. J. KALUBA, and L. Kestens, Isij Int. 43 (2003)

4. D. Muljono, M. Ferry, D. P. Dunne, Mater. Sci. Eng. A 303 (2001)

5. P. Roumen, H. Farideh, S. Jurij, M. Jesus, J. Sietsma, L. Kestens, Int. Virtual J. Mach. echnol. Mater. 8 (2012)

6. D. De Knijf, A. Puype, C. Föjer, and R. Petrov, Mater. Sci. Eng. A 627 (2015)

7. T. Link and B. Hance, Effects of strain rate and temperature on the work hardening behavior of high strength sheet steels (2003)

8. A. Puype, Development of advanced high strength steel via ultra fast annealing, Ghent University (2014)

9. J. Davim, Machining: fundamentals and recent advances (2008)

10. M. A. Meyers, Dynamic Behavior of Materials. Hoboken, NJ, USA: John Wiley \& Sons, Inc (1994)

11. P. Verleysen, J. Degrieck, T. Verstraete, and J. Van Slycken, Exp. Mech. 48 (2008)

12. P. Verleysen, J. Peirs, J. Van Slycken, K. Faes, L. Duchene, J. Mater. Process. Technol. 211 (2011)

13. J. Van Slycken, P. Verleysen, J. Degrieck, L. Samek, and B. C. de Cooman, Metall. Mater. Trans. A, 37 (2006)

14. T. Lolla, G. Cola, B. Narayanan, B. Alexandrov, S. S. Babu, Mater. Sci. Technol. 27 (2011)

15. F. M. Castro Cerda, F. Vercruysse, T. N. Minh, L. Kestens, A. Monsalve, R. Petrov, Steel Res. Int. 88 (2017)

16. F. M. Castro Cerda, I. Sabirov, C. Goulas, J. Sietsma, A. Monsalve, and R. H. Petrov, Mater. Des. 116 (2017)

17. G. Krauss, Martensite in steel: strength and structure, Mater. Sci. Eng. A 273 (1999)

18. T. Senuma, K. Kawasaki, Y. Takemoto, Mater. Trans. 47 (2006)

19. Y. Cao, J. Ahhström, B. Karlsson, J. Mater. Res. Technol. 4 (2015)

20. B. Farrokh, A.S. Khan, Int. J. Plast. 25 (2009) 